\title{
Use of the tumor-infiltrating CD8 to FOXP3 lymphocyte ratio in predicting treatment responses to combination therapy with pertuzumab, trastuzumab, and docetaxel for advanced HER2-positive breast cancer
}

Koji Takada', Shinichiro Kashiwagi ${ }^{1 *} \mathbb{D}$, Wataru Goto ${ }^{1}$, Yuka Asano ${ }^{1}$, Katsuyuki Takahashi ${ }^{2}$ Tsutomu Takashima', Shuhei Tomita ${ }^{2}$, Masahiko Ohsawa ${ }^{3}$, Kosei Hirakawa ${ }^{1}$ and Masaichi Ohira ${ }^{1}$

\begin{abstract}
Background: The trastuzumab, pertuzumab, and docetaxel (TPD) regimen is strongly recommended as a treatment option for first-line therapy for advanced human epidermal growth factor receptor (HER) 2-positive breast cancer. Monitoring the host microenvironments in cancer plays a significant role in predicting prognoses and curative effects. It is important to clarify the role of immune related gene expression in tumor-infiltrating lymphocytes in the tumor microenvironment. In this study, we evaluated the impact of chemotherapy with a TPD regimen, on immune micro environments in HER2-positive breast cancer using immune related proteins as indicators.

Methods: The subjects consisted of 30 patients who received the TPD regimen. The expression levels of estrogen receptor, progesterone receptor, Ki67, CD8, forkhead box protein (FOXP) 3, programmed death (PD) 1, programmed death ligand (PD-L) 1, CD163, phosphatase and tensin homolog and lymphocyte activation gene 3 were evaluated in biopsy specimens, by immunostaining.

Results: $\mathrm{CD} 8^{+}, \mathrm{CD} 8 / \mathrm{FOXP3}$ ratio $(\mathrm{CFR})^{\text {high }}$ and PD-L1 ${ }^{-}$group had significantly longer PFS than the CD8 ${ }^{-}, \mathrm{CFR}{ }^{\text {low }}$ and PDL1 ${ }^{+}$group $\left(p=0.045\right.$, log-rank) $\left(p=0.007\right.$, log-rank) $\left(p=0.040\right.$, log-rank), respectively. The CFR ${ }^{\text {high }}$ group had significantly better OS than the CFR ${ }^{\text {low }}$ group ( $p=0.034$, log-rank). In the univariate analysis, $C D 8^{+}, C F R^{\text {high }}$ groups extended PFS significantly $(p=0.027$, hazard ratio $[H R]=0.162)(p=0.008, H R=0.195)$, respectively. The receiver operating characteristic (ROC) analyses showed that the results for CFR [area under the curve (AUC): 0.708] were better than those for other factors (AUC: CD8 $=0.681, \mathrm{FOXP3}=0.639, \mathrm{PD} 1=0.528, \mathrm{PD}-\mathrm{L} 1=0.681$ ).
\end{abstract}

Conclusions: This study shows with the TPD regimen, a high CFR leads to a high ORR and long PFS in HER2-positive breast cancer. CFR, therefore, may be one of the important prognostic factors for this disease.

Keywords: Tumor-infiltrating lymphocytes, Breast cancer, Pertuzumab, HER2, CD8/FOXP3 ratio

\footnotetext{
*Correspondence: spqv9ke9@view.ocn.ne.jp

1 Department of Surgical Oncology, Osaka City University Graduate

School of Medicine, 1-4-3 Asahi-machi, Abeno-ku, Osaka 545-8585, Japan

Full list of author information is available at the end of the article
} 


\section{Background}

Human epidermal growth factor receptor (HER) 2, a tyrosine kinase transmembrane receptor, is associated with cellular growth and proliferation [1]. Overexpression of HER 2 occurs in about $20 \%$ of breast cancers and leads to poor prognosis [2]. However, various monoclonal antibodies for HER2 protein, such as pertuzumab, are currently used in clinical treatment along with chemotherapy to improve prognosis. HER2 signaling plays an important role in HER2-positive breast cancer (HER2-BC) [3-5], the prognosis of which has been greatly improved by anti-HER2 therapy, mainly with trastuzumab $[2,6]$. Large clinical trials have also shown that overall survival (OS) can be extended by treatment with pertuzumab [7-9], trastuzumab (a humanized monoclonal antibody), and trastuzumab emtansine (T-DM1; an antibody-drug conjugate) [10]. TPD regimen, consisting of trastuzumab, pertuzumab, and docetaxel, is the first choice of treatment for HER2-positive metastatic or recurrent breast cancer according to the National Comprehensive Cancer Network (NCCN) Guidelines Version 3.2015.

Monitoring the host microenvironments of cancer plays a significant role in predicting the prognoses and curative effects. Recently, there has an increase in reports that demonstrate the morphological evaluation of tumorinfiltrating lymphocytes (TILs) as well as its clinical implications in breast cancer. It is clear that TILs influence both the growth of various cancers and the action of anti-cancer drugs [11-14]. It is important to clarify the role of immune related genes in the tumor microenvironment. $\mathrm{CD}^{+}$cytotoxic $\mathrm{T}$ cells, lead to the death of tumor cells by apoptosis and improve prognosis [12]. In contrast, some cells, such as the regulatory $\mathrm{T}$ (Treg) cells and tumor associated macrophages (TAM), suppress anti-tumor immunity and promote proliferation of cancer [15-18]. We have previously reported the clinical validity and benefits of evaluating TILs for neoadjuvant chemotherapy (NAC). Chemotherapy with a TPD regimen (trastuzumab, pertuzumab, and docetaxel) has been established as the primary therapy for HER2-positive breast cancer and is garnering attention for its clinical outcomes and impact on cancer microenvironments. In this study, we evaluated the impact of chemotherapy with a TPD regimen, on immune micro environments in HER2-positive breast cancer using immune related proteins as indicators.

\section{Methods}

\section{Patient background}

This retrospective study was based on 30 patients with HER2-positive locally advanced or metastatic breast cancer, who received TPD regimen chemotherapy from
September 2013 to November 2015 at the Osaka City University Hospital, Osaka, Japan.

The pathological diagnosis of breast cancer was made by core needle biopsy (CNB) or vacuum assisted biopsy (VAB), and the stage was decided by computed tomography (CT), ultrasonography (US), and bone scintigraphy. The median follow-up period for the assessment of progression-free survival (PFS) and OS was 357 days (range 42-1015 days) and 497 days (range 91-735 weeks), respectively.

TPD regimen consists of trastuzumab, pertuzumab, and docetaxel (DTX). The loading dose of trastuzumab was $8 \mathrm{mg} / \mathrm{kg}$, and that of pertuzumab was $840 \mathrm{mg}$. The maintenance doses of trastuzumab and pertuzumab were $6 \mathrm{mg} / \mathrm{kg}$ and $420 \mathrm{mg}$, respectively every 3 weeks until disease progression. Six cycles of DTX were given at $75 \mathrm{mg} /$ $\mathrm{m}^{2} /$ cycle/3 weeks, but patients who were not healthy enough received 60 or $50 \mathrm{mg} / \mathrm{m}^{2}$ of DTX from the first cycle. If the doctors decided that continuing treatment with DTX was feasible, the patients underwent six additional cycles, but in the case of serious side effects, DTX was either reduced to $20-25 \%$ or was discontinued. At the end of the last cycle of DTX, all patients underwent imaging, and the outcomes were estimated in accordance with the response evaluation criteria in solid tumors (RECIST) criteria [19]. We defined the patients with objective response rate (ORR) as "Responders" and the others as "Non-responders".

The morphology of the tumor was evaluated using conventional hematoxylin and eosin (HE) staining. The expression of estrogen receptor (ER), progesterone receptor (PgR), HER2 and Ki67 in the CNB or VAB specimens obtained prior to the start of chemotherapy with the TPD regimen, were evaluated using immunostaining. In cases of untreated metastatic and recurrent breast cancers, biopsy samples obtained for diagnosis and a surgical specimen of first-line treatment respectively were analyzed. The diagnosis was made by several experienced pathologists specializing in cancer. While OS was defined as the period from the start of treatment to death, PFS was the period from the start of treatment to the date of death or confirmation of progression disease (PD), whichever came earlier.

\section{Ethics statement}

This study was conducted at Osaka City University Graduate School of Medicine, Osaka, Japan, according to the reporting recommendations for tumour marker prognostic studies (REMARK) guidelines and a retrospectively written, research, pathological evaluation, and statistical plan [20]. Informed consent was obtained from all patients. This research conformed to the provisions of the Declaration of Helsinki in 2013. The study protocol 
was approved by the Ethics Committee of the Osaka City University (\#926).

\section{Immunohistochemistry}

Immunohistochemistry studies were performed as described earlier [21]. Tumor specimens, which were fixed in $10 \%$ formaldehyde solution and embedded in paraffin, were sliced into $4-\mu \mathrm{m}$-thick sections and were mounted onto glass slides. The slides were deparaffinized in xylene and were incubated with $3 \%$ hydrogen peroxide in methanol for 15 min to block the endogenous peroxidase activity. Next, the specimens were heated for $10 \mathrm{~min}$ $\left(105^{\circ} \mathrm{C}\right)$ in an autoclave in the Target Retrieval Solution (Dako, Carpinteria, CA, USA). Primary monoclonal antibodies directed against ER (Dako, Cambridge, UK, clone 1D5, dilution 1:80;), PgR (Dako, clone PgR636, dilution 1:100; Dako), Ki-67 (Dako, clone MIB-1, dilution 1:100; Dako), HER2 (HercepTestTM; Dako), CD8 (Dako, clone C8/144B, dilution 1:150; Dako), forkhead box protein (FOXP) 3 (Abcam, Cambridge, UK, clone 236A/E7, dilution 1:150; Abcam, Cambridge, UK), programmed death
(PD) 1 (Abcam, clone NAT105, dilution 1:200; Abcam), programmed death ligand (PD-L) 1 (Abcam, clone 28-8, dilution 1:150; Abcam), CD163 (Leica, Newcastle, UK, clone 10 D6, dilution 1:200; Leica, Newcastle, UK), phosphatase and tensin homolog (PTEN) (Dako, clone 6H2.1, dilution 1:150; Dako), lymphocyte activation gene (LAG) 3 (Abcam, clone 11E3, dilution 1:150; Abcam) were used (Additional file 1: Table S1). These sections were incubated with each antibody for $70 \mathrm{~min}$ at room temperature or overnight at $4{ }^{\circ} \mathrm{C}$. Next, they were incubated for $10 \mathrm{~min}$ with horseradish peroxidase-conjugated anti-rabbit or anti-mouse Ig secondary antibodies [HISTOFINE (PO) TM kit; Nichirei, Tokyo, JAPAN]. Finally, the slides were treated with the streptavidin-peroxidase reagent and counterstained with Mayer's hematoxylin.

\section{Immunohistochemical evaluation}

The immunohistochemical staining was jointly scored by two breast pathologists (MOhs and STa), who were blinded to clinical information including treatments and outcomes. Based on the earlier study, samples with more

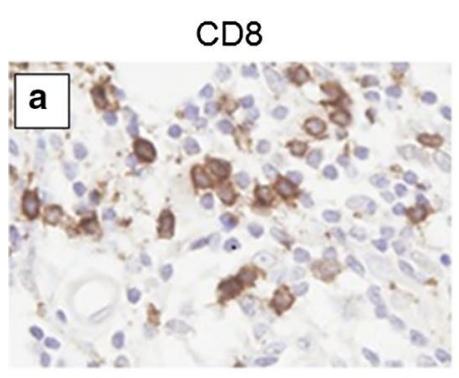

PD-L1

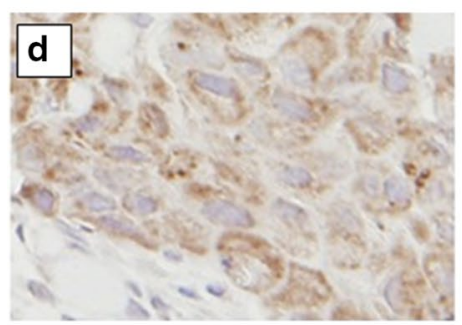

LAG3

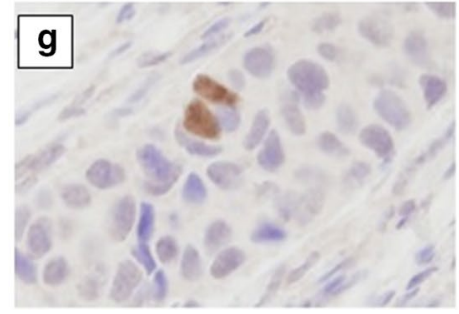

FOXP3

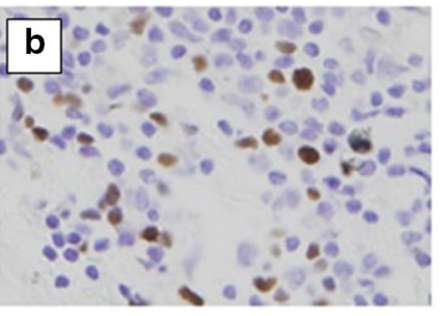

CD163

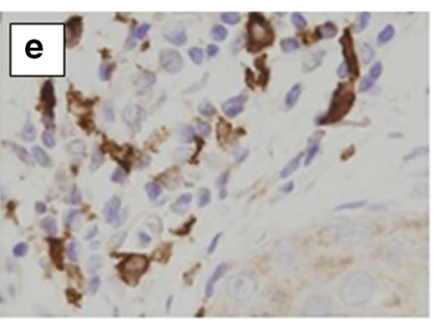

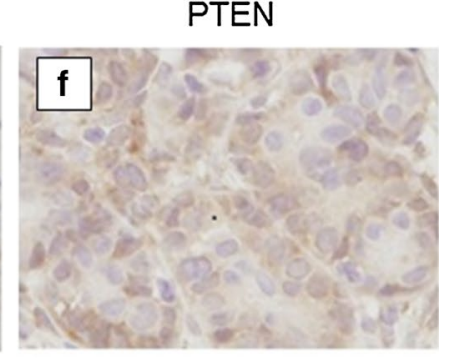

\section{PD1}

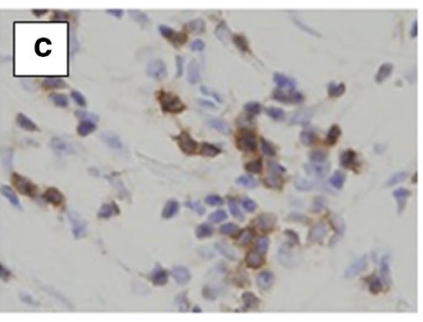

PTEN

Fig. 1 Evaluation of immune related proteins expression. These pictures were judged to be positive for expression (400-times magnification), Immunohistochemical staining using each monoclonal antibodies: a CD8, b FOXP3, c PD1, d PD-L1, e CD163, f PTEN, g LAG3 
than $1 \%$ staining were considered positive for ER and PgR, while those with less than $1 \%$ staining were counted as negative [22]. For Ki-67 expression, the cutoff was set at $14 \%$ based on the previous report [23]. TILs were evaluated in accordance with Salgado's report [11]. TILs were defined as the infiltrating lymphocytes within the tumor stroma and were expressed as a proportion of the field investigated. The area of TILs in the stroma surrounding the stained cancer cells was quantitatively measured. Each field under 400× magnification [24, 25].

Based on previous studies, CD8, FOXP3, and CD163 expression were calculated using the average of stained TILs in the area that was maximally stained, viewed at $400 \times$ magnification [26, 27]. PD1 and LAG3 expressions were evaluated similarly, except that a $200 \times$ magnification was used for visualization. The CD8/FOXP3 ratio (CFR) was calculated using the CD8 and FOXP3 results. PD-L1 and PTEN were evaluated at three randomly selected areas on the basis of a previous analysis. PDL1 was evaluated as a percentage of cells stained with cell membranes at moderate or strong [28]. On the other hand, PTEN expression was scored using immunoreactive scores (IRS), which is the product of SI (staining intensity) and PP (percentage of positive cells). SI was scored as 0, 1, 2 and 3 for negative, weak, moderate and strong staining respectively. PP was scored as $0(<1 \%), 1$ (1-10\%), 2 (11-50\%), 3 (51-80\%) and $4(>80 \%)$ [29]. The cutoff value for each of the immune related proteins was calculated by the median value and previous reports [28]. As a result, the cutoff for CD8 was 40, FOXP3 was 20, CFR was 1.6, PD1 was 20, PD-L1 was 10, CD163 was 40, PTEN was 5, and LAG3 was 5 (Fig. 1) (Additional file 1: Table S1).

\section{Statistical analysis}

Statistical analysis was performed using the JMP software (SAS, Tokyo, Japan). The relationship between each of immune related proteins and the ORR was examined by the Chi square test (or Fisher's exact test when necessary). The Kaplan-Meier method and the log-rank test compared high and low expression about PFS and OS. The hazard ratio (HR) and 95\% confidence intervals (CI) were calculated by the COX proportional hazards model. Univariate and multivariate analyses were performed by the Cox regression model and used in a backward stepwise method for variable selection in multivariate analysis. A $p$ value of less than 0.05 was considered significant.

\section{Results}

\section{Clinical characteristics}

Thirty patients were given TPD regimen, and their clinical characteristics are listed in Table 1 . The median age at the start of this regimen was 62 years (31-80 years).
Eighteen (60\%) and $20(66.7 \%)$ patients were negative for ER and PgR respectively. Four patients (13.3\%) were diagnosed with stage IIIC, 11 patients (36.7\%) with stage IV, and 15 patients (50.0\%) were diagnosed with a recurrence. The TPD regimen was used as the first line in 17 patients $(56.7 \%)$. The dose of DTX was reduced in ten patients because of side effects. The median course of DTX was 6 cycles (1-9 cycle). The ORR of all patients was $80.0 \%$ (3 patients showed a complete response (CR), while 21 had a partial response). With the progression

Table 1 Demographical data of 30 patients with TPD regimen for advanced HER2-positive breast cancer

\begin{tabular}{|c|c|}
\hline Parameters $(n=30)$ & Number of patients (\%) \\
\hline Age (years old) & $62(31-80)$ \\
\hline \multicolumn{2}{|l|}{ Degree of progress } \\
\hline $\begin{array}{l}\text { Locally advanced/visceral } \\
\text { metastases }\end{array}$ & $10(33.3 \%) / 20(66.7 \%)$ \\
\hline \multicolumn{2}{|l|}{ Stage } \\
\hline Stage IIIC/stage IV/recurrence & $4(13.3 \%) / 11(36.7 \%) / 15$ (50.0\%) \\
\hline \multicolumn{2}{|l|}{ Site of metastases } \\
\hline $\begin{array}{l}\text { Lung/bone/liver/brain/lymph } \\
\text { node/soft tissue }\end{array}$ & $\begin{array}{l}11(36.7 \%) / 12(40.0 \%) / 7(23.3 \%) / 3 \\
(10.0 \%) / 12(40.0 \%) / 11(36.6 \%)\end{array}$ \\
\hline \multicolumn{2}{|l|}{ Treatment line } \\
\hline First/other & $17(56.7 \%) / 13(43.3 \%)$ \\
\hline \multicolumn{2}{|l|}{ ER } \\
\hline Negative/positive & $18(60.0 \%) / 12(40.0 \%)$ \\
\hline \multicolumn{2}{|l|}{$\mathrm{PgR}$} \\
\hline Negative/positive & $20(66.7 \%) / 10(33.3 \%)$ \\
\hline \multicolumn{2}{|l|}{ Ki67 } \\
\hline Negative/positive & $16(55.2 \%) / 14(44.8 \%)$ \\
\hline \multicolumn{2}{|l|}{ CD8 } \\
\hline Negative/positive & $21(70.0 \%) / 9(30.0 \%)$ \\
\hline \multicolumn{2}{|l|}{ FOXP3 } \\
\hline Negative/positive & $15(50.0 \%) / 15$ (50.0\%) \\
\hline \multicolumn{2}{|l|}{ CFR } \\
\hline Low/high & $15(50.0 \%) / 15$ (50.0\%) \\
\hline \multicolumn{2}{|l|}{ PD1 } \\
\hline Negative/positive & $14(46.7 \%) / 16(53.3 \%)$ \\
\hline \multicolumn{2}{|l|}{ PD-L1 } \\
\hline Negative/positive & $19(63.3 \%) / 11$ (36.7\%) \\
\hline \multicolumn{2}{|l|}{ CD163 } \\
\hline Negative/positive & $15(50.0 \%) / 15$ (50.0\%) \\
\hline \multicolumn{2}{|l|}{ PTEN } \\
\hline Negative/positive & $17(56.7 \%) / 13(43.3 \%)$ \\
\hline \multicolumn{2}{|l|}{ LAG3 } \\
\hline Negative/positive & $20(66.7 \%) / 10(33.3 \%)$ \\
\hline
\end{tabular}

TPD, trastuzumab, pertuzumab, docetaxel; HER2, human epidermal growth factor receptor 2; ER, estrogen receptor; PgR, progesterone receptor; FOXP3, forkhead box protein 3; CFR, CD8/FOXP3 ratio; PD1, programmed death 1; PD-L1, programmed death ligand-1; PTEN, phosphatase and tensin homolog; LAG3, lymphocyte activation gene 3 
Table 2 Correlation between immune related proteins and objective response rate (ORR) in 30 advanced HER2-positive breast cancer

\begin{tabular}{|c|c|c|c|}
\hline Parameters & Responders $(n=25)$ & Non-responders $(n=5)$ & $p$ value \\
\hline \multicolumn{4}{|l|}{ Age at treatment } \\
\hline$\leq 62$ vs $>62$ & $12(48.0 \%)$ vs $13(52.0 \%)$ & $3(60.0 \%) / 2(40.0 \%)$ & 0.638 \\
\hline \multicolumn{4}{|l|}{ Degree of progress } \\
\hline Locally advanced vs visceral metastases & $9(36.0 \%) / 16(64.0 \%)$ & $1(20.0 \%) / 4(80.0 \%)$ & 0.505 \\
\hline \multicolumn{4}{|l|}{ Stage } \\
\hline IIIC or IV vs recurrence & $12(48.8 \%) / 13(52.0 \%)$ & $3(60.0 \%) / 2(40.0 \%)$ & 0.638 \\
\hline \multicolumn{4}{|l|}{ ER } \\
\hline Negative vs positive & $16(64.0 \%) / 9(36.0 \%)$ & $2(40.0 \%) / 3(60.0 \%)$ & 0.334 \\
\hline \multicolumn{4}{|l|}{$\mathrm{PgR}$} \\
\hline Negative vs positive & $17(68.0 \%) / 8(32.0 \%)$ & $3(60.0 \%) / 2(40.0 \%)$ & 0.740 \\
\hline \multicolumn{4}{|l|}{ Ki67 } \\
\hline Negative vs positive & $14(56.0 \%) / 11(44.4 \%)$ & $2(40.0 \%) / 3(60.0 \%)$ & 0.529 \\
\hline \multicolumn{4}{|l|}{ Treatment line } \\
\hline First vs other & $16(64.0 \%) / 9(36.0 \%)$ & $1(20.0 \%) / 4(80.0 \%)$ & 0.074 \\
\hline \multicolumn{4}{|l|}{ CD8 } \\
\hline Negative vs positive & $16(64.0 \%) / 9(36.0 \%)$ & $5(100.0 \%) / 0(0.0 \%)$ & 0.116 \\
\hline \multicolumn{4}{|l|}{ FOXP3 } \\
\hline Negative vs positive & $12(48.8 \%) / 13(52.0 \%)$ & $3(60.0 \%) / 2(40.0 \%)$ & 0.638 \\
\hline \multicolumn{4}{|l|}{ CFR } \\
\hline Low/high & $10(40.0 \%) / 15(60.0 \%)$ & $5(100.0 \%) / 0(0.0 \%)$ & 0.013 \\
\hline \multicolumn{4}{|l|}{ PD1 } \\
\hline Negative vs positive & $11(44.0 \%) / 14(56.0 \%)$ & $3(60.0 \%) / 2(40.0 \%)$ & 0.529 \\
\hline \multicolumn{4}{|l|}{ PD-L1 } \\
\hline Negative vs positive & $17(68.0 \%) / 8(32.0 \%)$ & $2(40.0 \%) / 3(60.0 \%)$ & 0.250 \\
\hline \multicolumn{4}{|l|}{ CD163 } \\
\hline Negative vs positive & $12(48.8 \%) / 13(52.0 \%)$ & $3(60.0 \%) / 2(40.0 \%)$ & 0.638 \\
\hline \multicolumn{4}{|l|}{ PTEN } \\
\hline Negative vs positive & $13(52.0 \%) / 12(48.8 \%)$ & $4(80.0 \%) / 1(20.0 \%)$ & 0.264 \\
\hline \multicolumn{4}{|l|}{ LAG3 } \\
\hline Negative vs positive & 16 (64.0\%)/9 (36.0\%) & $4(80.0 \%) / 1(20.0 \%)$ & 0.505 \\
\hline
\end{tabular}

ORR, objective response rate; HER2, human epidermal growth factor receptor 2; ER, estrogen receptor; PgR, progesterone receptor; FOXP3, forkhead box protein 3; CFR, CD8/FOXP3 ratio; PD1, programmed death 1; PD-L1, programmed death ligand-1; PTEN, phosphatase and tensin homolog; LAG3, lymphocyte activation gene 3

of HER2-positive breast cancer, 6 patients were moved to trastuzumab emtansine therapy, and 4 patients were given eribulin or capecitabine. While 4 patients died of breast cancer, 1 died of another disease, and yet another patient died of an unknown cause.

\section{Association of each immune-related protein with ORR, PFS, and OS}

When evaluating ORR, CFR ${ }^{\text {high }}$ group had significantly better ORR than CFR $^{\text {low }}$ group $(\mathrm{p}=0.013)$ (Table 2). There was no relationship between ORR and other immune related proteins. $\mathrm{CD}^{+}, \mathrm{CFR}^{\text {high }}$ and $\mathrm{PD}-\mathrm{L1}^{-}$ group had significantly longer PFS than negative $\mathrm{CD} 8^{-}$, $\mathrm{CFR}^{\text {low }}$ and $\mathrm{PDL}^{+}$group $(\mathrm{p}=0.045, \log$-rank $)(\mathrm{p}=0.007$, log-rank) ( $\mathrm{p}=0.040, \log$-rank), respectively (Fig. 2$)$. The
CFR ${ }^{\text {high }}$ groups also had significantly better OS than the $\mathrm{CFR}^{\text {low }}$ groups $(\mathrm{p}=0.034$, log-rank) (Fig. 3). Expression of other immune related proteins was not related to both PFS and OS.

In a univariate analysis, $\mathrm{CD}^{+}, \mathrm{CFR}^{\text {high }}$ group made a significant contribution to extending PFS in patients with advanced HER2-positive breast cancer $(\mathrm{p}=0.027$, hazard ratio $[H R]=0.162)(p=0.008, H R=0.195)$, respectively (Fig. 4a). However, a multivariate analysis revealed that $\mathrm{CD}^{+}, \mathrm{CFR}^{\text {high }}$ and PD-L1 ${ }^{-}$group was not an independent factor $(p=0.292, H R=0.333)(p=0.149, H R=0.336)$ $(\mathrm{p}=0.582, \mathrm{HR}=1.441)$ (Table 3$)$.

Receiver operating characteristic (ROC) analyses showed that, for advanced HER2-positive breast cancer patients, the CFR results [area under the curve 

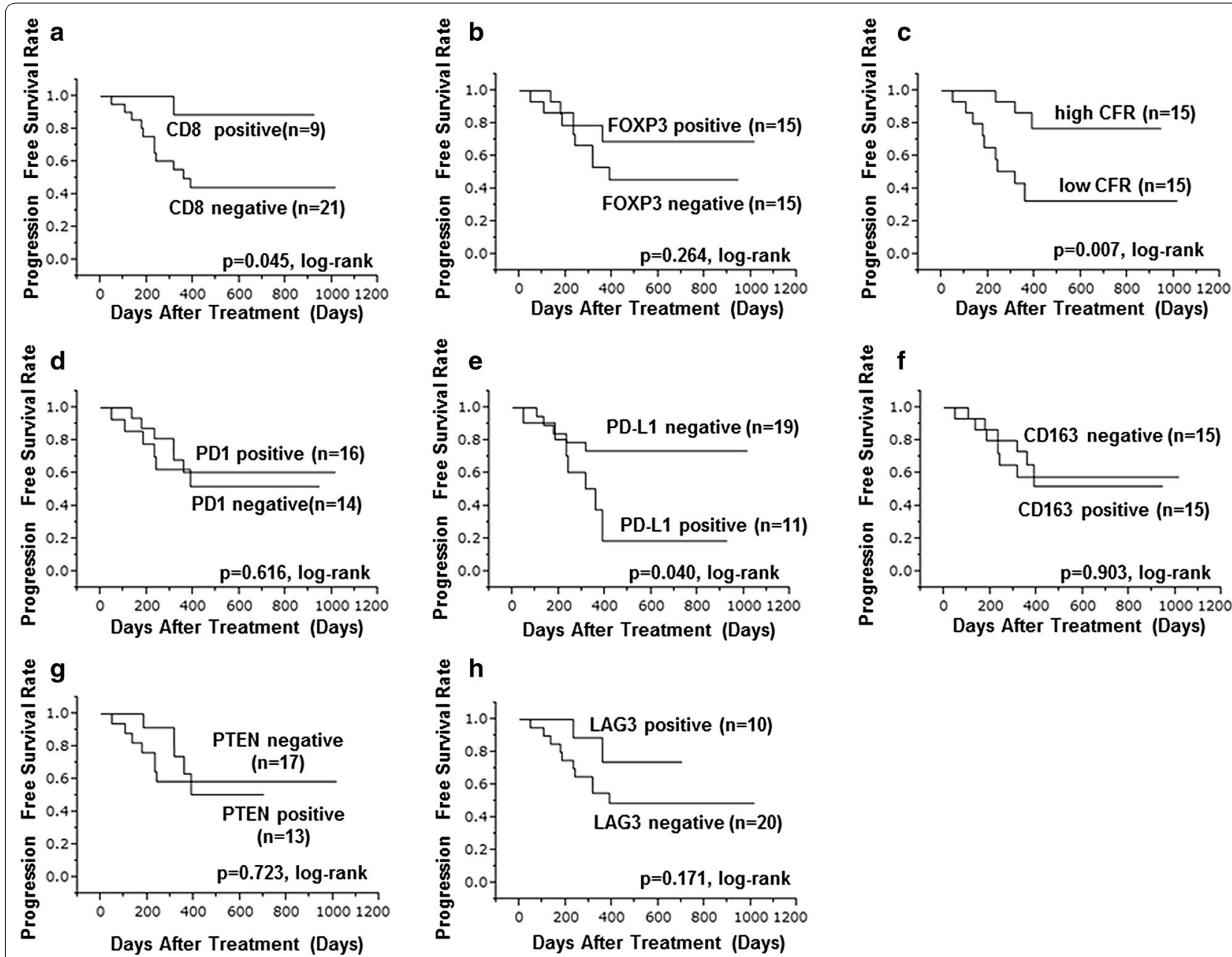

Fig. 2 PFS with advanced HER2-positive breast cancer on immune related protein. Positive CD8, CFR ${ }^{\text {high }}$ group and negative PDL1 group had significantly longer PFS than negative CD8, CFR ${ }^{\text {low }}$ group and positive PDL1 group, respectively: a $(p=0.045, \log$-rank), $\mathbf{c}(p=0.007, \log$-rank), e ( $p=0.040$, log-rank). Other immune related protein expression were not related to PFS: b FOXP3, d PD1, f CD163, g PTEN, h LAG3

(AUC): 0.708] were better than those for the other factors (AUC: CD8 $=0.681, \mathrm{FOXP} 3=0.639, \mathrm{PD} 1=0.528$, PD-L1 =0.681) (Fig. 4b).

\section{Discussion}

The tumor microenvironment plays an important role in cancer treatments. TILs are known to affect the tumor growth and the antitumor treatments in various cancers [30-33]. Among the TILs, cytotoxic $\mathrm{CD}^{+}$cells play an important role in antitumor effect [31]. Conversely, there are some cells and proteins that promote tumor proliferation or suppress the antitumor effects of $\mathrm{CD}^{+} \mathrm{T}$ cells. Treg cells which express FOXP3, belong to this class and inhibit the $\mathrm{CD}^{+}$T-cells [30]. As the proportion of FOXP3 increases, it interferes with the activity of $\mathrm{CD}^{+}$ $\mathrm{T}$ cells, even in the presence of high levels of CD8, and therefore, CFR was used in some studies.
PD1, a transmembrane protein expressed on T cells, B cells and natural killer $\mathrm{T}$ cells, regulates immune tolerance and autoimmunity [31]. PD1 has two ligands PDL1 and PDL2 [30]. While PDL2 is expressed on dendritic cells and macrophages, PDL1 is expressed not only on resting $\mathrm{T}$ cells, $\mathrm{B}$ cells, dendritic cells, and macrophages but also on a number of different cancer cells [30, 32]. Due to its inhibitory effect on the antitumoral T cell-mediated immunity, the PD1/PDL1 pathway is a poor prognostic indicator in various cancers [32-36]. Studies have shown that the inhibition of PD1/PDL1 pathway enhances the antibody-dependent cell-mediated cytotoxicity (ADCC) of natural killer cells and induces apoptosis in tumor cells [37-39]. Furthermore, Paul et al. have demonstrated that the therapeutic effects of targeting PD1 are related to the $\mathrm{CD}^{+} \mathrm{T}$ cells in invasive cancer prior to therapy [40]. CD163, a single-chain transmembrane protein expressed 

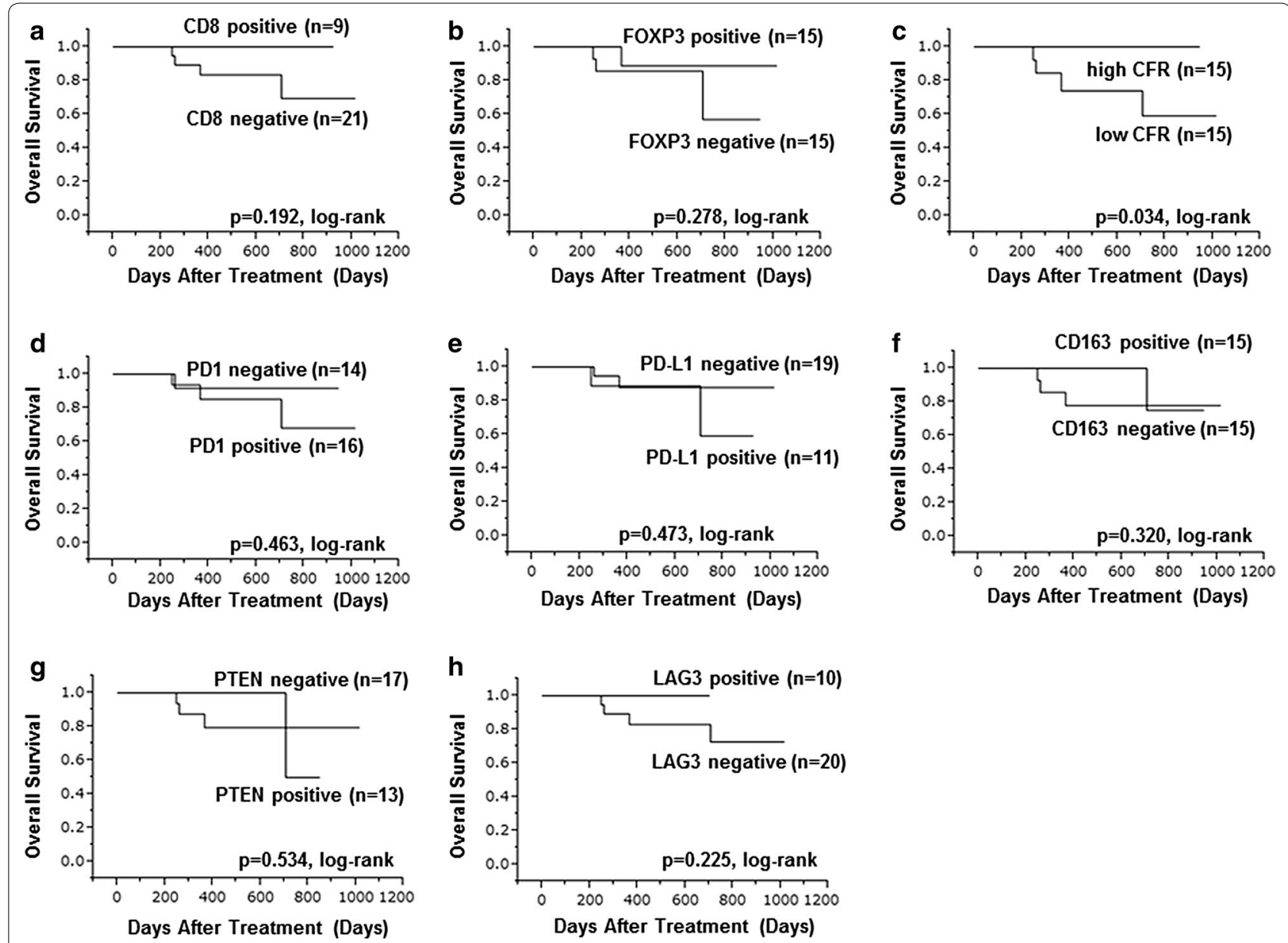

Fig. 3 OS with advanced HER2-positive breast cancer on immune related protein. Positive or high groups had significantly better OS than negative or low group about CFR (c) ( $p=0.034$, log-rank). Other immune related protein expression were not related to OS: a CD8, b FOXP3, d PD1, e PD-L1, $\mathbf{f}$ CD163, g PTEN, h LAG3
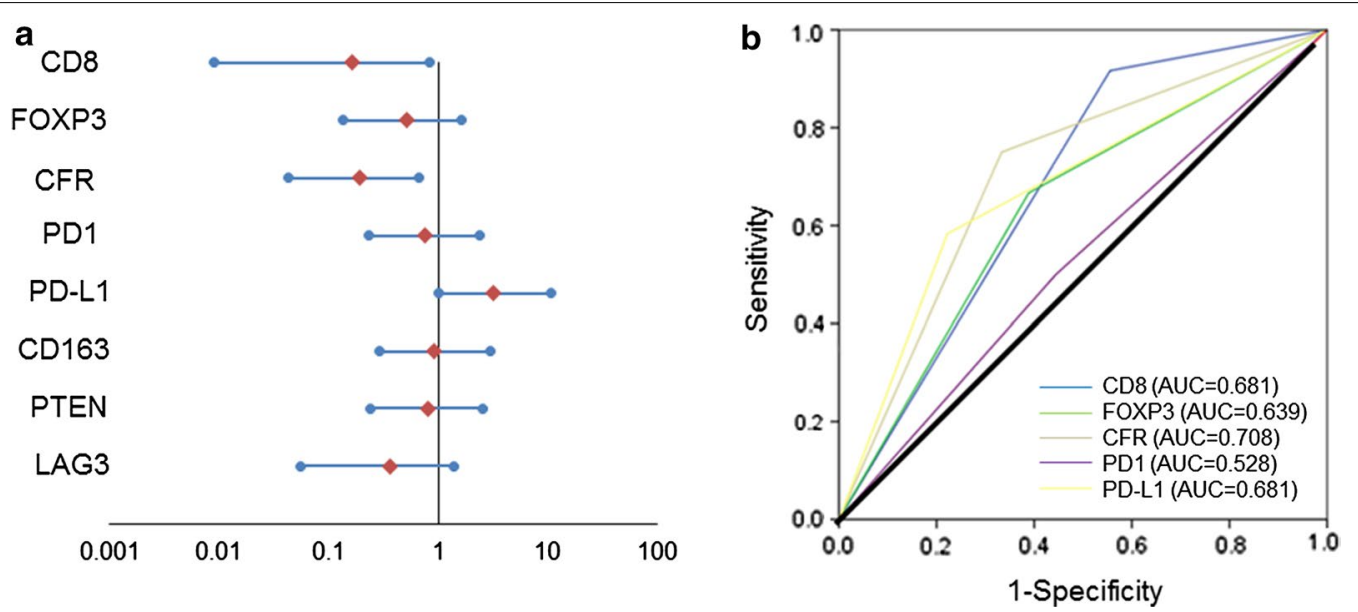

Fig. 4 Forest plots and on ROC analyses. a In univariate analysis, positive CD8, CFR high group made a significant contribution to extending PFS in patients with advanced HER2-positive breast cancer, respectively $(p=0.027, H R=0.162)(p=0.008, H R=0.195)$. b ROC analyses showed that, for advanced HER2-positive breast cancer patients, the results for the CFR (AUC: CFR $=0.708$ ) were better than those for the other factors (AUC: $\mathrm{CD} 8=0.681, \mathrm{FOXP3}=0.639, \mathrm{PD} 1=0.528, \mathrm{PD}-\mathrm{L} 1=0.681$ ) 
Table 3 Univariate and multivariate analysis with respect to progression free survival (PFS) in 30 advanced HER2positive breast cancer

\begin{tabular}{|c|c|c|c|c|c|c|}
\hline \multirow[t]{2}{*}{ Parameters } & \multicolumn{3}{|l|}{ Univariate } & \multicolumn{3}{|l|}{ Multivariate } \\
\hline & Hazard ratio & $95 \% \mathrm{Cl}$ & $p$ value & Hazard ratio & $95 \% \mathrm{Cl}$ & $p$ value \\
\hline \multicolumn{7}{|l|}{ Age at treatment } \\
\hline$\leq 62$ vs $>62$ & 1.271 & $0.395-4.096$ & 0.680 & & & \\
\hline \multicolumn{7}{|l|}{ Degree of progress } \\
\hline $\begin{array}{l}\text { Locally advanced vs visceral } \\
\text { metastases }\end{array}$ & 0.934 & $0.293-3.505$ & 0.912 & & & \\
\hline \multicolumn{7}{|l|}{ Stage } \\
\hline IIIC or IV vs recurrence & 1.260 & $0.402-4.263$ & 0.692 & & & \\
\hline \multicolumn{7}{|l|}{ ER } \\
\hline Negative vs positive & 1.581 & $0.494-5.063$ & 0.431 & & & \\
\hline \multicolumn{7}{|l|}{$\mathrm{PgR}$} \\
\hline Negative vs positive & 0.925 & $0.246-2.948$ & 0.898 & & & \\
\hline \multicolumn{7}{|l|}{ Ki67 } \\
\hline Negative vs positive & 1.066 & $0.333-3.410$ & 0.912 & & & \\
\hline \multicolumn{7}{|l|}{ Treatment line } \\
\hline First vs other & 1.449 & $0.452-4.643$ & 0.522 & & & \\
\hline \multicolumn{7}{|l|}{ CD8 } \\
\hline Negative vs positive & 0.162 & $0.009-0.837$ & 0.027 & 0.333 & $0.017-2.349$ & 0.292 \\
\hline \multicolumn{7}{|l|}{ FOXP3 } \\
\hline Negative vs positive & 0.513 & $0.137-1.632$ & 0.263 & & & \\
\hline \multicolumn{7}{|l|}{ CFR } \\
\hline Low/high & 0.195 & $0.043-0.664$ & 0.008 & 0.336 & $0.062-1.455$ & 0.149 \\
\hline \multicolumn{7}{|l|}{ PD1 } \\
\hline Negative vs positive & 0.751 & $0.234-2.404$ & 0.620 & & & \\
\hline \multicolumn{7}{|l|}{ PD-L1 } \\
\hline Negative vs positive & 3.147 & $0.994-10.754$ & 0.051 & 1.441 & $0.400-5.768$ & 0.582 \\
\hline \multicolumn{7}{|l|}{ CD163 } \\
\hline Negative vs positive & 0.932 & $0.291-2.992$ & 0.904 & & & \\
\hline \multicolumn{7}{|l|}{ PTEN } \\
\hline Negative vs positive & 0.814 & $0.240-2.556$ & 0.725 & & & \\
\hline \multicolumn{7}{|l|}{ LAG3 } \\
\hline Negative vs positive & 0.364 & $0.056-1.386$ & 0.149 & & & \\
\hline
\end{tabular}

PFS, progression free survival; HER2, human epidermal growth factor receptor 2; $\mathrm{Cl}$, confidence intervals; ER, estrogen receptor; PgR, progesterone receptor; FOXP3, forkhead box protein 3; CFR, CD8/FOXP3 ratio; PD1, programmed death 1; PD-L1, programmed death ligand-1; PTEN, phosphatase and tensin homolog; LAG3, lymphocyte activation gene 3

in mature macrophages and monocytes, is regarded as a specific marker for M2 macrophages [41]. Macrophages are divided into a classically activated phenotype (M1) and an alternatively activated phenotype (M2). TAM are M2 macrophages which are in and around the tumor [17]. Therefore, in this study, we studied CD163 expression by immunostaining to identify TAM. TAM produce a variety of immunosuppressive molecules and promote angiogenesis and tissue remodeling [42]. These features accelerate tumor growth and contribute to poor prognosis in most cancers, including breast cancer $[17,41]$. LAG3, also known as CD223, is expressed on natural killer cells, B cells, and dendritic cells. It binds to MHC class II [43]. Recent studies have shown LAG3 is expressed on $\mathrm{CD} 8^{+} \mathrm{T}$ cells and Treg cells in TILs, and it inhibits the activity of $\mathrm{CD}^{+} \mathrm{T}$ cells $[43,44]$. Therefore, new drugs that block the interaction between LAG3 and MHC class II are being clinically studied.

Although we have described the relationship between immune related proteins and chemotherapy, there are very few reports that study molecular targeted drugs. We, therefore, investigated the role of the immune system in a typical chemotherapy including molecular targeted drugs, such as TPD therapy. Trastuzumab has been 
used as a monoclonal antibody for HER2 protein before pertuzumab. Trastuzumab emtansine combination has been used in the clinic, but most patients develop resistance to trastuzumab within a year [45]. Reduced PTEN expression has been reported to be the most likely cause of resistance [46]. PTEN antagonizes phosphatidylinositol 3-kinase function and regulates Akt activities. We suspect that a similar mechanism might be in play during the TPD regimen, but it is yet to be confirmed.

As a limitation of this study, protein expression was only retrospectively assessed by immunostaining. In order to show the relationship between tumor and its immune microenvironment, it is necessary to evaluate at the gene level and prove it with vitro. However, CFR or PDL1 expression was significantly correlated with PFS, as seen from the univariate analysis. Moreover, a higher CFR was correlated with a better ORR and a longer PFS in the multivariate analyses. These results suggest that the good immune tumor microenvironment enhance the antitumor effects of TPD therapy. It was suggested that CFR is the most sensitive indicator about the immune tumor microenvironment monitoring in TPD regimen chemotherapy.

\section{Conclusions}

This study shows that high CFR leads to high ORR and long PFS under TPD regimen in HER2-positive breast cancer and that CFR may become one of the prognostic factors. We present the importance of cancer microenvironment in tumor immunology among anti-tumor treatment and reaffirmed the necessity of examining improvement methods in tumor immunology for patients diagnosed with poor prognosis including low CFR group in the future.

\section{Additional file}

Additional file 1: Table S1. Primary antibodies for immunohistochemistry and immunohistochemical evaluation.

\section{Authors' contributions}

KTakad and SK participated in the design of the study and drafted the manuscript. SK helped with study data collection and manuscript preparation. WG, YA, KTakah, TT and ST helped with study data collection and participated in its design. MOhs helped with pathological diagnosis. $\mathrm{KH}$ and MOhi conceived the study, and participated in its design and coordination and helped to draft the manuscript. All authors read and approved the final manuscript.

\section{Author details \\ ${ }^{1}$ Department of Surgical Oncology, Osaka City University Graduate School of Medicine, 1-4-3 Asahi-machi, Abeno-ku, Osaka 545-8585, Japan. ${ }^{2}$ Depart- ment of Pharmacology, Osaka City University Graduate School of Medicine, 1-4-3 Asahi-machi, Abeno-ku, Osaka 545-8585, Japan. ${ }^{3}$ Department of Diag- nostic Pathology, Osaka City University Graduate School of Medicine, 1-4-3 Asahi-machi, Abeno-ku, Osaka 545-8585, Japan.}

\section{Acknowledgements}

We thank Sayaka Tanaka (STa) (Department of Diagnostic Pathology, Osaka City University Graduate School of Medicine) for helpful advice regarding pathological diagnosis. We thank Yayoi Matsukiyo and Tomomi Okawa (Department of Surgical Oncology, Osaka City University Graduate School of Medicine) for helpful advice regarding data management.

\section{Competing interests}

The authors declare that they have no competing interests.

\section{Availability of data and materials}

The datasets supporting the conclusions of this article is included within the article.

\section{Consent for publication}

Written informed consent was obtained from all patients.

\section{Ethics approval and consent to participate}

Written informed consent was obtained from all subjects. This research conformed to the provisions of the declaration of Helsinki in 2013. All patients were informed of the investigational nature of this study and provided their written, informed consent. The study protocol was approved by the Ethics Committee of Osaka City University (\#926).

\section{Funding}

This study was funded by grants from the Japan Society for the Promotion of Science (KAKENHI, Nos. 25461992, 26461957, and 17K10559) to Shinichiro Kashiwagi.

\section{Publisher's Note}

Springer Nature remains neutral with regard to jurisdictional claims in published maps and institutional affiliations.

Received: 16 October 2017 Accepted: 27 March 2018

Published online: 03 April 2018

\footnotetext{
Abbreviations

TPD: trastuzumab, pertuzumab, docetaxel; HER2: human epidermal growth factor receptor 2; TILs: tumor-infiltrating lymphocytes; ER: estrogen receptor; PgR: progesterone receptor; FOXP3: forkhead box protein 3; PD-1: programmed death-1; PD-L1: programmed death-ligand 1; PTEN: phosphatase and tensin homolog; LAG3: lymphocyte activation gene 3; CFR: CD8/FOXP3 ratio; HR: hazard ratio; ROC: receiver operating characteristic; AUC: area under the curve; BC: breast cancer; OS: overall survival; T-DM1: trastuzumab emtansine; NCCN: National Comprehensive Cancer Network; Treg: regulatory T; TAM: tumor associated macrophages; NAC: neoadjuvant chemotherapy; CNB: core needle biopsy; VAB: vacuum assisted biopsy; CT: computed tomography; US: ultrasonography; PFS: progression-free survival; DTX: docetaxel; RECIST: response evaluation criteria in solid tumors; ORR: objective response rate; HE: hematoxylin and eosin; PD: progression disease; REMARK: reporting recommendations for tumour marker prognostic studies; IRS: immunoreactive scores; Cl: confidence intervals; ADCC: antibody-dependent cell-mediated cytotoxicity.
}

\section{References}

1. Hynes NE, Lane HA. ERBB receptors and cancer: the complexity of targeted inhibitors. Nat Rev Cancer. 2005;5(5):341-54.

2. Slamon DJ, Leyland-Jones B, Shak S, Fuchs H, Paton V, Bajamonde A, Fleming T, Eiermann W, Wolter J, Pegram M, et al. Use of chemotherapy plus a monoclonal antibody against HER2 for metastatic breast cancer that overexpresses HER2. N Engl J Med. 2001;344(11):783-92.

3. Slamon DJ, Godolphin W, Jones LA, Holt JA, Wong SG, Keith DE, Levin WJ, Stuart SG, Udove J, Ullrich A, et al. Studies of the HER-2/ neu proto-oncogene in human breast and ovarian cancer. Science. 1989;244(4905):707-12.

4. Slamon DJ, Clark GM, Wong SG, Levin WJ, Ullrich A, McGuire WL. Human breast cancer: correlation of relapse and survival with amplification of the HER-2/neu oncogene. Science. 1987;235(4785):177-82. 
5. Chia S, Norris B, Speers C, Cheang M, Gilks B, Gown AM, Huntsman D, Olivotto IA, Nielsen TO, Gelmon K. Human epidermal growth factor receptor 2 overexpression as a prognostic factor in a large tissue microarray series of node-negative breast cancers. J Clin Oncol. 2008;26(35):5697-704

6. Dawood S, Broglio K, Buzdar AU, Hortobagyi GN, Giordano SH. Prognosis of women with metastatic breast cancer by HER2 status and trastuzumab treatment: an institutional-based review. J Clin Oncol. 2010;28(1):92-8.

7. Baselga J, Cortes J, Im SA, Clark E, Ross G, Kiermaier A, Swain SM. Biomarker analyses in CLEOPATRA: a phase III, placebo-controlled study of pertuzumab in human epidermal growth factor receptor 2-positive, first-line metastatic breast cancer. J Clin Oncol. 2014;32(33):3753-61.

8. Baselga J, Cortes J, Kim SB, Im SA, Hegg R, Im YH, Roman L, Pedrini JL, Pienkowski T, Knott A, et al. Pertuzumab plus trastuzumab plus docetaxel for metastatic breast cancer. N Engl J Med. 2012;366(2):109-19.

9. Kawajiri H, Takashima T, Kashiwagi S, Noda S, Onoda N, Hirakawa K. Pertuzumab in combination with trastuzumab and docetaxel for HER2-positive metastatic breast cancer. Expert Rev Anticancer Ther. 2015;15(1):17-26.

10. Verma S, Miles D, Gianni L, Krop IE, Welslau M, Baselga J, Pegram M, Oh DY, Dieras V, Guardino E, et al. Trastuzumab emtansine for HER2-positive advanced breast cancer. N Engl J Med. 2012;367(19):1783-91.

11. Salgado R, Denkert C, Demaria S, Sirtaine N, Klauschen F, Pruneri G, Wienert S, Van den Eynden G, Baehner FL, Penault-Llorca F, et al. The evaluation of tumor-infiltrating lymphocytes (TILS) in breast cancer: recommendations by an International TILs working group 2014. Ann Oncol. 2015;26(2):259-71.

12. Fridman WH, Pages F, Sautes-Fridman C, Galon J. The immune contexture in human tumours: impact on clinical outcome. Nat Rev Cancer. 2012;12(4):298-306.

13. Kocian P, Sedivcova M, Drgac J, Cerna K, Hoch J, Kodet R, Bartunkova J, Spisek R, Fialova A. Tumor-infiltrating lymphocytes and dendritic cells in human colorectal cancer: their relationship to KRAS mutational status and disease recurrence. Hum Immunol. 2011;72(11):1022-8.

14. Liu H, Zhang T, Ye J, Li H, Huang J, Li X, Wu B, Huang X, Hou J. Tumorinfiltrating lymphocytes predict response to chemotherapy in patients with advance non-small cell lung cancer. Cancer Immunol Immunother 2012;61(10):1849-56.

15. Sakaguchi S, Sakaguchi N, Asano M, Itoh M, Toda M. Immunologic selftolerance maintained by activated $\mathrm{T}$ cells expressing $\mathrm{IL}-2$ receptor alphachains (CD25). Breakdown of a single mechanism of self-tolerance causes various autoimmune diseases. J Immunol. 1995;155(3):1151-64.

16. Liyanage UK, Moore TT, Joo HG, Tanaka Y, Herrmann V, Doherty G, Drebin JA, Strasberg SM, Eberlein TJ, Goedegebuure PS, et al. Prevalence of regulatory T cells is increased in peripheral blood and tumor microenvironment of patients with pancreas or breast adenocarcinoma. J Immunol. 2002;169(5):2756-61.

17. Komohara Y, Jinushi M, Takeya M. Clinical significance of macrophage heterogeneity in human malignant tumors. Cancer Sci. 2014;105(1):1-8.

18. Jacobs JF, Idema AJ, Bol KF, Grotenhuis JA, de Vries IJ, Wesseling P, Adema GJ. Prognostic significance and mechanism of Treg infiltration in human brain tumors. J Neuroimmunol. 2010;225(1-2):195-9.

19. Eisenhauer EA, Therasse P, Bogaerts J, Schwartz LH, Sargent D, Ford R, Dancey J, Arbuck S, Gwyther S, Mooney M, et al. New response evaluation criteria in solid tumours: revised RECIST guideline (version 1.1). Eur J Cancer. 2009;45(2):228-47.

20. McShane LM, Altman DG, Sauerbrei W, Taube SE, Gion M, Clark GM. Statistics Subcommittee of the NCIEWGoCD: reporting recommendations for tumor marker prognostic studies. J Clin Oncol. 2005;23(36):9067-72.

21. Kashiwagi S, Yashiro M, Takashima T, Aomatsu N, Kawajiri H, Ogawa Y, Onoda N, Ishikawa T, Wakasa K, Hirakawa K. c-Kit expression as a prognostic molecular marker in patients with basal-like breast cancer. Br J Surg. 2013;100(4):490-6.

22. Yamashita H, Yando Y, Nishio M, Zhang Z, Hamaguchi M, Mita K, Kobayashi S, Fujii Y, Iwase H. Immunohistochemical evaluation of hormone receptor status for predicting response to endocrine therapy in metastatic breast cancer. Breast Cancer. 2006;13(1):74-83.

23. Cheang MC, Chia SK, Voduc D, Gao D, Leung S, Snider J, Watson M, Davies S, Bernard PS, Parker JS, et al. Ki67 index, HER2 status, and prognosis of patients with luminal B breast cancer. J Natl Cancer Inst. 2009;101(10):736-50
24. Ono M, Tsuda H, Shimizu C, Yamamoto S, Shibata T, Yamamoto H, Hirata T, Yonemori K, Ando M, Tamura K, et al. Tumor-infiltrating lymphocytes are correlated with response to neoadjuvant chemotherapy in triple-negative breast cancer. Breast Cancer Res Treat. 2012;132(3):793-805.

25. Kashiwagi S, Asano Y, Goto W, Takada K, Takahashi K, Noda S, Takashima T, Onoda N, Tomita S, Ohsawa M, et al. Use of tumor-infiltrating lymphocytes (TILs) to predict the treatment response to eribulin chemotherapy in breast cancer. PLoS ONE. 2017;12(2):e0170634.

26. Asano Y, Kashiwagi S, Goto W, Kurata K, Noda S, Takashima T, Onoda N, Tanaka S, Ohsawa M, Hirakawa K. Tumour-infiltrating CD8 to FOXP3 lymphocyte ratio in predicting treatment responses to neoadjuvant chemotherapy of aggressive breast cancer. Br J Surg. 2016;103(7):845-54.

27. Miyashita M, Sasano H, Tamaki K, Hirakawa H, Takahashi Y, Nakagawa S, Watanabe G, Tada H, Suzuki A, Ohuchi N, et al. Prognostic significance of tumor-infiltrating $\mathrm{CD}^{+}$and $\mathrm{FOXP3}^{+}$lymphocytes in residual tumors and alterations in these parameters after neoadjuvant chemotherapy in triple-negative breast cancer: a retrospective multicenter study. Breast Cancer Res. 2015;17:124.

28. Nomi T, Sho M, Akahori T, Hamada K, Kubo A, Kanehiro H, Nakamura S, Enomoto K, Yagita H, Azuma M, et al. Clinical significance and therapeutic potential of the programmed death-1 ligand/programmed death-1 pathway in human pancreatic cancer. Clin Cancer Res. 2007;13(7):2151-7.

29. Nagata Y, Lan KH, Zhou X, Tan M, Esteva FJ, Sahin AA, Klos KS, Li P, Monia $B P$, Nguyen NT, et al. PTEN activation contributes to tumor inhibition by trastuzumab, and loss of PTEN predicts trastuzumab resistance in patients. Cancer Cell. 2004;6(2):117-27.

30. Hori S, Nomura T, Sakaguchi S. Control of regulatory T cell development by the transcription factor Foxp3. Science. 2003;299(5609):1057-61.

31. Keir ME, Butte MJ, Freeman GJ, Sharpe AH. PD-1 and its ligands in tolerance and immunity. Annu Rev Immunol. 2008;26:677-704.

32. Hamanishi J, Mandai M, Iwasaki M, Okazaki T, Tanaka Y, Yamaguchi K, Higuchi T, Yagi H, Takakura K, Minato N, et al. Programmed cell death 1 ligand 1 and tumor-infiltrating $C D 8^{+}$T lymphocytes are prognostic factors of human ovarian cancer. Proc Natl Acad Sci USA. 2007;104(9):3360-5.

33. Thompson RH, Gillett MD, Cheville JC, Lohse CM, Dong H, Webster WS, Krejci KG, Lobo JR, Sengupta S, Chen L, et al. Costimulatory B7-H1 in renal cell carcinoma patients: indicator of tumor aggressiveness and potential therapeutic target. Proc Natl Acad Sci USA. 2004;101(49):17174-9.

34. Ohigashi Y, Sho M, Yamada Y, Tsurui Y, Hamada K, Ikeda N, Mizuno T, Yoriki $\mathrm{R}$, Kashizuka $\mathrm{H}$, Yane $\mathrm{K}$, et al. Clinical significance of programmed death-1 ligand-1 and programmed death-1 ligand-2 expression in human esophageal cancer. Clin Cancer Res. 2005;11 (8):2947-53.

35. Hino R, Kabashima K, Kato Y, Yagi H, Nakamura M, Honjo T, Okazaki T, Tokura Y. Tumor cell expression of programmed cell death-1 ligand 1 is a prognostic factor for malignant melanoma. Cancer. 2010;1 16(7):1757-66.

36. Muenst S, Schaerli AR, Gao F, Daster S, Trella E, Droeser RA, Muraro MG, Zajac P, Zanetti R, Gillanders WE, et al. Expression of programmed death ligand 1 (PD-L1) is associated with poor prognosis in human breast cancer. Breast Cancer Res Treat. 2014;146(1):15-24.

37. Benson DM Jr, Bakan CE, Mishra A, Hofmeister CC, Efebera Y, Becknell B, Baiocchi RA, Zhang J, Yu J, Smith MK, et al. The PD-1/PD-L1 axis modulates the natural killer cell versus multiple myeloma effect: a therapeutic target for CT-011, a novel monoclonal anti-PD-1 antibody. Blood. 2010;116(13):2286-94.

38. Hayashi T, Hideshima T, Akiyama M, Podar K, Yasui H, Raje N, Kumar S, Chauhan D, Treon SP, Richardson P, et al. Molecular mechanisms whereby immunomodulatory drugs activate natural killer cells: clinical application. Br J Haematol. 2005; 128(2):192-203.

39. Zhu D, Corral LG, Fleming YW, Stein B. Immunomodulatory drugs Revlimid (lenalidomide) and CC-4047 induce apoptosis of both hematological and solid tumor cells through NK cell activation. Cancer Immunol Immunother. 2008;57(12):1849-59.

40. Tumeh PC, Harview CL, Yearley JH, Shintaku IP, Taylor EJ, Robert L, Chmielowski B, Spasic M, Henry G, Ciobanu V, et al. PD-1 blockade induces responses by inhibiting adaptive immune resistance. Nature. 2014;515(7528):568-71.

41. Medrek C, Ponten F, Jirstrom K, Leandersson K. The presence of tumor associated macrophages in tumor stroma as a prognostic marker for breast cancer patients. BMC Cancer. 2012;12:306. 
42. Ostuni R, Kratochvill F, Murray PJ, Natoli G. Macrophages and cancer: from mechanisms to therapeutic implications. Trends Immunol. 2015;36(4):229-39.

43. He Y, Rivard CJ, Rozeboom L, Yu H, Ellison K, Kowalewski A, Zhou C, Hirsch FR. Lymphocyte-activation gene-3, an important immune checkpoint in cancer. Cancer Sci. 2016;107(9):1193-7.

44. Grosso JF, Kelleher CC, Harris TJ, Maris CH, Hipkiss EL, De Marzo A, Anders R, Netto G, Getnet D, Bruno TC, et al. LAG-3 regulates CD8 ${ }^{+}$T cell accumulation and effector function in murine self- and tumor-tolerance systems. J Clin Invest. 2007;117(11):3383-92.
45. Esteva FJ, Valero V, Booser D, Guerra LT, Murray JL, Pusztai L, Cristofanilli M, Arun B, Esmaeli B, Fritsche HA, et al. Phase II study of weekly docetaxel and trastuzumab for patients with HER-2-overexpressing metastatic breast cancer. J Clin Oncol. 2002;20(7):1800-8.

46. Gong C, Yao Y, Wang Y, Liu B, Wu W, Chen J, Su F, Yao H, Song E. Upregulation of miR-21 mediates resistance to trastuzumab therapy for breast cancer. J Biol Chem. 2011;286(21):19127-37.

\section{Submit your next manuscript to BioMed Central and we will help you at every step:}

- We accept pre-submission inquiries

- Our selector tool helps you to find the most relevant journal

- We provide round the clock customer support

- Convenient online submission

- Thorough peer review

- Inclusion in PubMed and all major indexing services

- Maximum visibility for your research

Submit your manuscript at

www.biomedcentral com/submit 